\title{
RANCANG BANGUNG PERANGKAT LUNAK PEMBELAJARAN FISIKA BERBASIS COMPUTER ASSISTED INSTRUCTION PADA SMP ST. IGNATIUS MEDAN
}

\author{
Tiarma Simanihuruk $^{\# 1}$, Hartono $^{\# 2}$ \\ ${ }^{\# 1,2}$ Program Studi Teknik Informatika, STMIK IBBI Medan-Indonesia \\ Email: ${ }^{1}$ tiarma.simanihuruk@gmail.com, ${ }^{2}$ hartonoibbi@gmail.com
}

\begin{abstract}
Abstrak
Inovasi di dalam bidang pembelajaran sangat dibutuhkan oleh seorang pendidik, untuk menjadikan materi yang mereka sampaikan menjadi lebih menarik. Pada saat ini sudah berkembang perangkat lunak pembelajaran berbasis Compuster Assisted Instruction yang merupakan suatu perangkat lunak pembelajaran berbasis multimedia sehingga akan meningkatkan daya tarik peserta didik di dalam mendalami suatu materi pembelajaran. Suatu materi pembelajaran yang sulit akan menjadi lebih menarik jika menggunakan pendekatan Computer Assisted Instruction. Pada penelitian ini akan dikembangkan perangkat lunak pembelajaran Fisika SMP berbasis Computer Assisted Instruction pada SMP St. Ignatius Medan. Metode penelitian yang digunakan di dalam penelitian ini adalah metode SDLC (System Development Life Cycle) yang merupakan suatu medotologi perancangan yang sangat baik karena mengidentifikasikan dengan baik kebutuhan pemakai. Bentuk implementasi penelitian ini adalah merancang suatu program pembelajaran Fisik pada tingkat SMP. Program dapat menampilkan materi, contoh perhitungan, dan contoh-contoh soal yang berhubungan dengan topik massa dan volume, kecepatan tetap, serta gaya dan tekanan.
\end{abstract}

Kata Kunci: Perangkat Lunak, Computer Assisted Instruction, System Development Life Cycle

\section{PENDAHULUAN}

Modul pembelajaran mengenai suatu topik untuk pelajaran di sekolah banyak dikembangkan dalam bentuk program multimedia yang dikemas dalam CD-ROM ataupun dalam bentuk DVD (Digital Versatile Disc). Keuntungan dari program-program pembelajaran ini adalah tampilan yang menarik disertai dengan animasi dan video sehingga pemahaman mengenai suatu topik menjadi lebih mudah.

Ada berbagai macam materi pelajaran yang dapat dikemas dalam bentuk perangkat lunak berbasis multimedia yang dikenal sebagai CAI (Computer Assisted Instruction), salah satu diantaranya adalah materi tentang pembelajaran mata pelajaran fisika untuk tingkat SMP. Seperti diketahui mata pelajaran fisika ini biasanya sangat sulit dimengerti oleh sebagian siswa. Dengan memanfaatkan komputer multimedia maka pemahaman mengenai topik fisika menjadi lebih mudah selain itu materi yang dikemas dalam bentuk digital tersebut memudahkan para guru dalam penyampaian materi seperti tidak perlu dicatat berulang kali di papan tulis sehingga lebih menghemat waktu. Bagi siswa sendiri dengan adanya perangkat lunak pembelajaran maka siswa dapat mengulang materi tanpa kehadiran guru dan dapat meningkatkan daya tarik dan minat belajar siswa.

Penelitian ini bertujuan untuk membuat perangkat lunak belajar fisika SMP berbasis multimedia pada SMP St. Ignatius Medan dan dapat digunakan sebagai teaching aid (alat bantu pengajaran) sehingga memudahkan siswa dalam belajar topik fisika dasar. Perangkat lunak dirancang dengan menggunakan bahasa pemrograman Visual Basic versi 6.0.

Berdasarkan latar belakang masalah tersebut maka dirancang suatu sistem pembelajaran berbasis multimedia yang menerapkan konsep belajar sambil bermain. Untuk memudahkan dalam penyampaian materi, maka materi dikemas secara menarik dalam bentuk multimedia yang bersifat mendidik sekaligus menghibur bagi anak-anak. 


\section{KAJIAN PUSTAKA}

\subsection{Perangkat Lunak Ajak Berbantuan Komputer}

Konsep dasar dan tujuan perangkat ajar atau CAI (Computer Assisted Instruction) harus diketahui sebelum melakukan perancangan. pembelajaran berbasiskan komputer dikenal CAI (Computer Assisted Learning) merupakan sebuah model pembelajaran menggunakan komputer sebagai media pendukungnya. (Hutahaean, 2012:1).

Perangkat Ajar yang dibantu oleh komputer atau Computer Assisted Instruction (CAI) adalah pengajaran dengan menggunakan perangkat aplikasi (application software) yang dirancang untuk menghasilkan metode dan materi pengajaran suatu topik dengan tujuan memberikan fasilitas belajar yang lebih mudah. Adapun Tujuan dari penerapan Perangkat Ajar berbasis CAI digolongkan lagi menjadi tujuan yang lebih khusus, yaitu: (Science Encyclopedia, 2005: 1)

1. Peningkatan Pengawasan

2. Penggunaan Kebutuhan Sumber Daya

3. Individualisasi

4. Ketepatan Waktu dan Tingkat Ketersediaan

5. Pengurangan Waktu Latihan

6. Perbaikan Hasil Kerja

7. Sebagai Alat Yang Nyaman Dipakai

8. Alat Mengubah Cara Belajar

9. Peningkatan Kepuasan Belajar

10. Pengurangan Waktu Pengembangan

\subsection{Komponen-Komponen Dasar Perangkat Lunak Ajar}

Sistem pengajaran berbasis komputer ini terdiri dari empat komponen utama, yaitu perangkat

keras (hardware), perangkat lunak (software), perangkat ajar (courseware) dan tenaga manusia (humanware). (Science Encyclopedia, 2005:

1. Perangkat Keras (hardware)

Komponen ini meliputi semua peralatan secara fisik yang berhubungan dengan sistem pelatihan berbasis komputer, termasuk terminal komputer, disk drive, printer, multimedia, jaringan komputer dan sebagainya.

2. Perangkat Lunak (software)

Yang dimaksud dengan perangkat lunak dalam hal ini adalah semua program yang dapat dioperasikan dan melakukan fungsi-fungsi instruksional. Perangkat lunak ini dapat diklasifikasikan menjadi perangkat lunak sistem, perangkat lunak aplikasi dan perangkat lunak pengajaran.

3. Perangkat Ajar (courseware)

Perangkat ajar merupakan salah satu perangkat lunak, namun dalam sistem pelatihan berbasis komputer ini, perangkat ajar dibedakan dari perangkat lunak lainnya karena mempunyai aturan khusus untuk menampilkan suatu materi pendidikan.

4. Tenaga Manusia (humanware)

Yang dimaksud dengan tenaga manusia (humanware) adalah orang-orang dengan keahlian khusus yang mengembangkan, mengoperasikan, memelihara atau menyesuaikan suatu sistem pengajaran berbasis multimedia.Menurut Lukmanul Hakim (2009) Web OnLine merupakan suatu sarana untuk menampilkan diri Anda (Kantor, Profil Perusahaan, Pribadi) di Internet secara cepat. Dapat diibaratkan web online hampir serupa dengan Website yaitu sebuah tempat di Internet, siapa saja di dunia ini dapat mengunjunginya, kapan saja mereka dapat mengetahui tentang Anda, memberi pertanyaan kepada Anda, memberikan masukan atau bahkan mengetahui dan membeli produk Anda. Dengan demikian web online dapat memberikan informasi secara real time dan dengan waktu yang sangat singkat sekali, dimana informasi ditulis dan dapat dilihat langsung oleh ribuan pengunjung yang melihat website tersebut. Sehingga web online dapat disebut sebuah sarana baru untuk mempromosikan produk, jasa atau apapun yang akan di berikan melalui media Internet secara langsung. 


\subsection{Media Pembelajaran}

Istilah media berasal dari bahasa latin yang merupakan bentuk jamak dari medium. Secara harfiah berarti perantara atau pengantar. Pengertian umumnya adalah segala sesuatu yang dapat menyalurkan informasi dari sumber informasi kepada penerima informasi. (Ardiani Mustikasari, 2008)

Istilah pembelajaran lebih menggambarkan usaha guru untuk membuat belajar para siswanya. Kegiatan pembelajaran tidak akan berarti jika tidak menghasilkan kegiatan belajar pada para siswanya. Kegiatan belajar hanya akan berhasil jika si belajar secara aktif mengalami sendiri proses belajar. Seorang guru tidak dapat mewakili belajar siswanya. Seorang siswa belum dapat dikatakan telah belajar hanya karena ia sedang berada dalam satu ruangan dengan guru yang sedang mengajar.

Pekerjaan mengajar tidak selalu harus diartikan sebagai kegiatan menyajikan materi pelajaran. Meskipun penyajian materi pelajaran memang merupakan bagian dari kegiatan pembelajaran, tetapi bukanlah satu-satunya. Masih banyak cara lain yang dapat dilakukan guru untuk membuat siswa belajar. Peran yang seharusnya dilakukan guru adalah mengusahakan agar setiap siswa dapat berinteraksi secara aktif dengan berbagai sumber balajar yang ada.

Media pembelajaran adalah media yang digunakan dalam pembelajaran, yaitu meliputi alat bantu guru dalam mengajar serta sarana pembawa pesan dari sumber belajar ke penerima pesan belajar (siswa). Sebagai penyaji dan penyalur pesan, media belajar dalam hal-hal tertentu bisa mewakili guru menyajiakan informasi belajar kepada siswa. Jika program media itu didesain dan dikembangkan secara baik, maka fungsi itu akan dapat diperankan oleh media meskipun tanpa keberadaan guru.

Peranan media yang semakin meningkat sering menimbulkan kekhawatiran pada guru. Namun sebenarnya hal itu tidak perlu terjadi, masih banyak tugas guru yang lain seperti: memberikan perhatian dan bimbingan secara individual kepada siswa yang selama ini kurang mendapat perhatian. Kondisi ini akan teus terjadi selama guru menganggap dirinya merupakan sumber belajar satu-satunya bagi siswa. Jika guru memanfaatkan berbagai media pembelajaran secara baik, guru dapat berbagi peran dengan media. Peran guru akan lebih mengarah sebagai manajer pembelajaran dan bertanggung jawab menciptakan kondisi sedemikian rupa agar siswa dapat belajar. Untuk itu guru lebih berfubgsi sebagai penasehat, pembimbing, motivator dan fasilitator dalam Kegiatan Belajar mengajar.

\subsection{Analisa dan Perancangan Sistem}

Menurut Sutabri (2004) kata analisis diartikan sebagai: "Penguraian suatu pokok atas berbagai bagiannya dan penelaahan bagian itu sendiri, serta hubungan antar bagian untuk memperoleh pengertian yang tepat dan pemahaman arti keseluruhan."

Perancangan sistem dapat didefinisikan sebagai penggambaran, perencanaan dan pembuatan sketas atau pengaturan dari beberapa elemen yang terpisah ke dalam satu kesatuan yang utuh dan berfungsi. Perancangan sistem menentukan bagaimana suatu sistem akan menyelesaikan apa yang mesti diselesaikan; tahap ini menyangkut mengkonfigurasikan dari komponen-komponen perangkat lunak dan perangkat keras dari suatu sistem, sehingga setelah instalasi dari sistem akan benar-benar memuaskan rancang bangun yang telah ditetapkan pada akhir tahap analisis sistem. Perancangan sistem dapat dibagi dalam 2 bagian yaitu:

1. Perancangan sistem secara umum / perancangan konseptual, perancangan logikal / perancangan secara makro.

2. Perancangan sistem terinci / perancangan sistem secara fisik.

\subsection{Teorema Fisika Dasar}

\subsubsection{Volume dan Massa Jenis}

Salah satu ciri khas zat adalah massa jenisnya. Dengan kata lain, zat-zat yang sejenis memiliki massa jenis yang sama, dan zat-zat yang jenisnya berbeda memiliki massa jenis yang berbeda. Volume ialah jumlah ruang yang ditempati oleh suatu benda berdimensi tiga dan diukur dalam satuan kubik (misalnya liter, $\mathrm{m}^{3}, \mathrm{~cm}^{3}$ ). Untuk menentukan massa jenis suatu benda, perlu diketahui dua besaran, yakni massa dan volumnya. Massa jenis didefinisikan sebagai massa benda per satuan volum. Jika lambang massa jenis $\rho$, volum $\mathbf{V}$, dan massa $\mathbf{m}$, rumus untuk massa jenis adalah :

$$
\rho=\mathrm{m} / \mathrm{v}
$$




\subsubsection{Gerak Lurus}

Benda yang bergerak lurus terhadap benda lain berubah jaraknya terhadap benda itu menurut waktu tempuhnya. Jarak yang ditempuh tiap sekon disebut kecepatan. Jika jarak yang ditempuh benda yang bergerak itu sama untuk tiap sekon, maka benda itu dikatakan mempunyai kecepatan tetap. Gerak benda yang demikian disebut gerak beraturan.Lambang untuk jarak ialah $s$, waktu tempuh $t$, dan kecepatan tetap $v$. Untuk gerak lurus beraturan berlaku rumus:

Kecepatan tetap = Jarak $/$ Waktu Tempuh

$$
\mathrm{v}=\mathrm{s} / \mathrm{t}
$$

Satuan kecepatan adalah $\mathrm{m} / \mathrm{s}$.

\section{METODE PENELITIAN}

\subsection{Tahapan Penelitian}

Tahapan-tahapan penelitian yang dapat dilakukan sebagai berikut :

1. Melakukan analisa kebutuhan terkait dengan masing-masing karakteristik.

2. Melakukan perancangan proses pada masing-masing karakteristik.

3. Melakukan implementasi hasil perancangan.

4. Melakukan pengujian aplikasi.

5. Menyusun laporan penelitian.

6. Publikasi laporan penelitian.

\subsection{Metode Pengumpulan Data}

Pengumpulan data dilakukan melalui studi kasus dan pustaka dengan mempelajari analisa sistem (system analyzing) dan desain fungsi (Design Function).

\subsection{Metode Perancangan}

Metode perancangan perangkat lunak menggunakan Metode SDLC (System Development Life Cycle) yang terdiri dari 7 tahapan. Adapun tahapan dan langkah-langkah pengembangan perangkat lunak pembelajaran fisika berbasis Computer Assisted Instruction dengan metode SDLC ini dapat digambarkan dalam bentuk diagram alir seperti dapat dilihat pada Gambar 1.

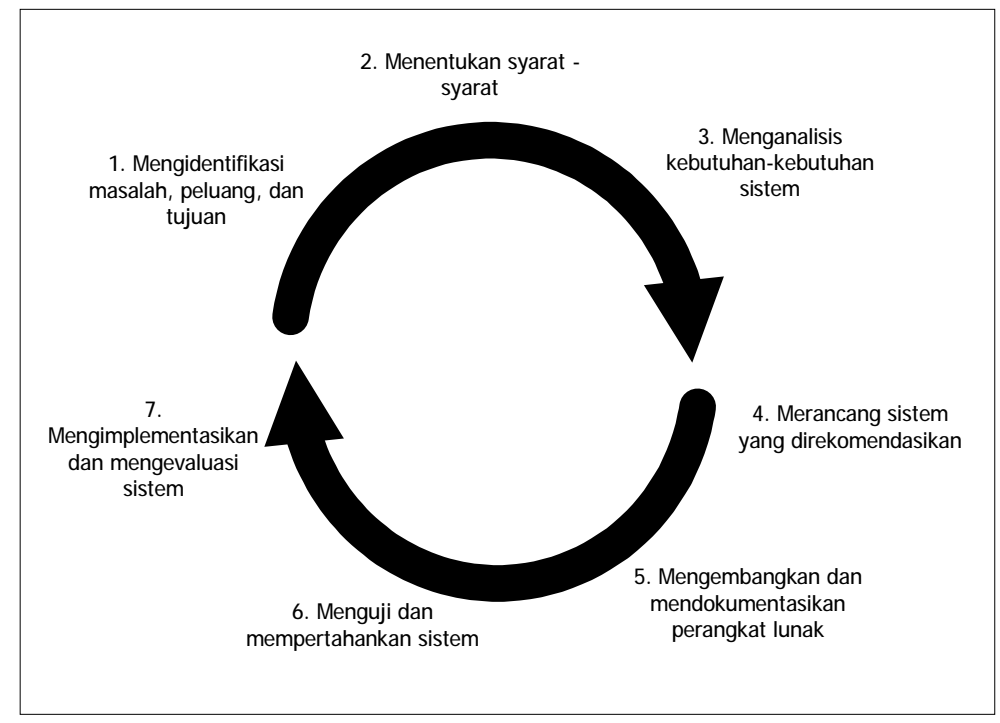

Gambar 1. Metodologi Perancangan 


\subsection{Metode Pengujian}

Pengujian sistem dilakukan untuk mengetahui apakah sistem tersebut sudah berjalan sesuai dengan yang direncanakan. Hal ini sangat penting karena dapat memberikan informasi bila terjadi kesalahan pada sistem dan tentunya dapat segera dicari solusi pada bagian mana sistem tersebut harus diperbaiki.

\section{HASIL DAN PEMBAHASAN}

\subsection{Tampilan Awal Aplikasi}

Adapun tampilan awal dari hasil perancangan peneliti mengenai aplikasi pembelajaran fisika berbasis Computer Assisted Instruction (CAI) dapat dilihat pada Gambar 2.

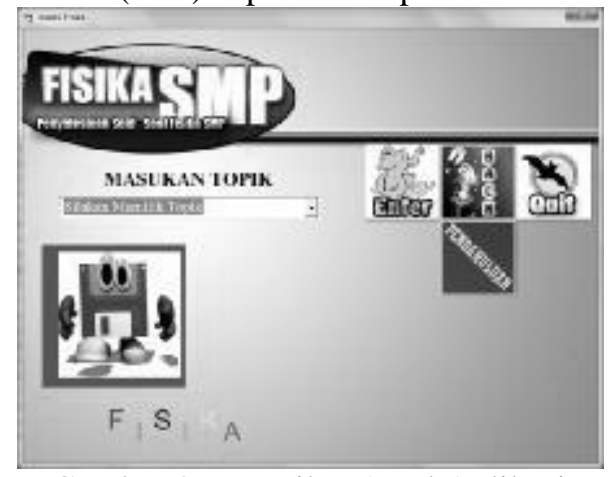

Gambar 2. Tampilan Awal Aplikasi

\subsection{Menu Pemilihan Topik}

Terdapat 4 (topik) pembahasan yang dapat dilipih, yaitu: Volume dan Masaa Jenis, Kecepatan Tetap, Gaya dan Tekanan, dan Berat dan Massa. Adapun tampilan pemilihan topik dapat dilihat pada Gambar 3.

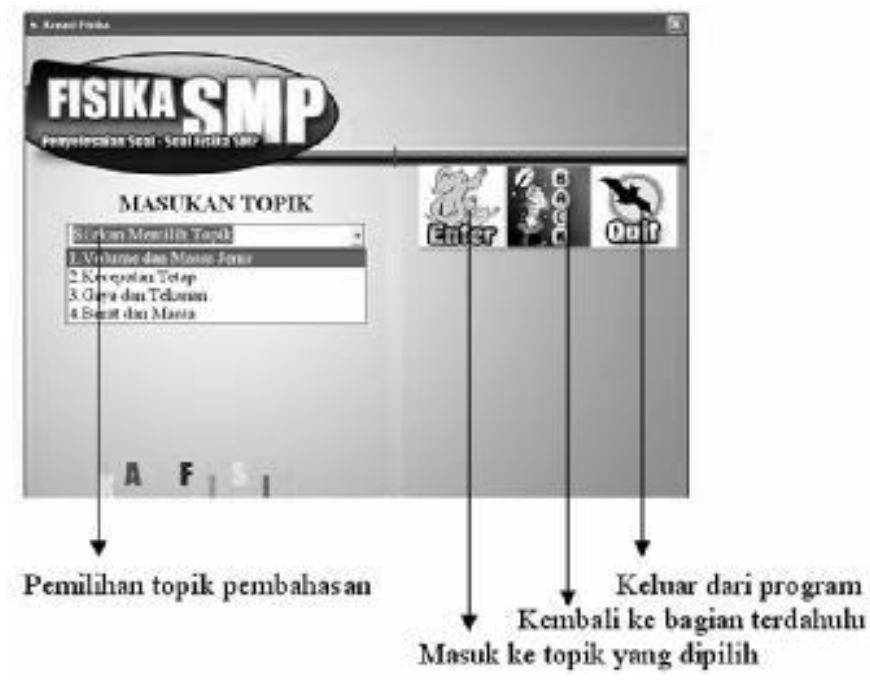

Gambar 3. Menu Pemilihan Topik 


\subsection{Sub Menu untuk Tiap Kategori}

Untuk tiap kategori yang dipilih, terdiri-atas 3 sub menu yaitu: Teori, Contoh Soal, dan Penyelesaian. Adapun tampilan sub menu untuk tiap kategori dapat dilihat pada Gambar 4.

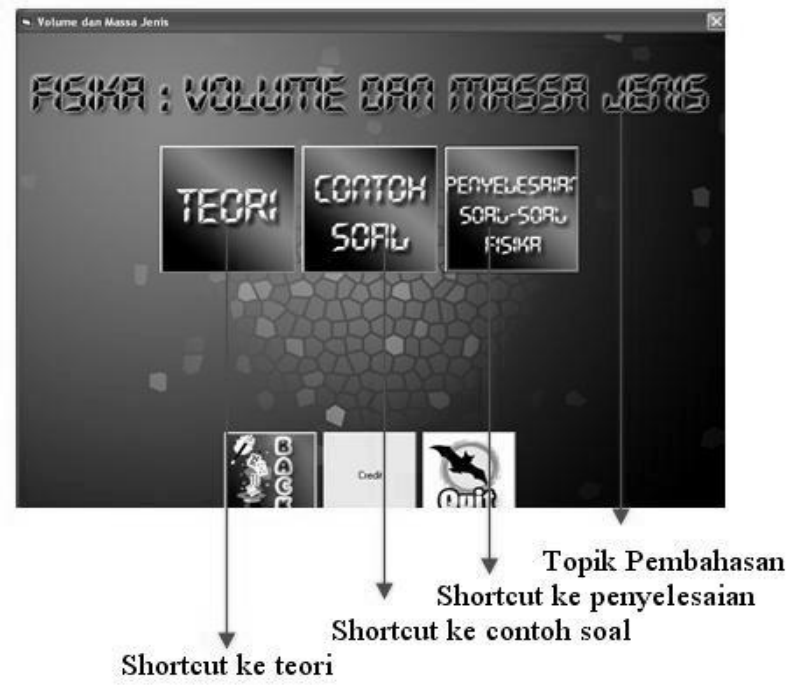

Gambar 4. Sub Menu untuk Tiap Kategori

\section{KESIMPULAN DAN SARAN}

\subsection{Kesimpulan}

Berdasarkan penelitian yang dilakukan oleh peneliti, maka terdapat beberapa hal yang dapat disimpulkan sebagai berikut.

1. Dengan memanfaatkan fasilitas multimedia dan beberapa aplikasi untuk membuat animasi, dan suara maka perancangan aplikasi multimedia seperti pembelajaran mengenai penyelesaian soal-soal fisika dapat lebih mudah dilakukan.

2. Program pembelajaran mengenai soal-soal fisika ini dilengkapi dengan soal-soal latihan untuk menguji pemahaman atas topik yang telah ditampilkan pada program.

3. Hasil dari perancangan aplikasi ini maka dapat dijadikan suatu program untuk memperkenalkan dan mempelajari topik fisika dasar.

4. Perangkat belajar berbantuan komputer dengan pendekatan multimedia dapat meningkatkan minat belajar pada siswa terutama mengenai fisika dasar.

\subsection{Saran} berikut:

Untuk pengembangan lebih lanjut dari program ini maka dapat diberikan beberapa saran sebagai

1. Menambahkan pembahasan pada program untuk topik fisika lainnya.

2. Menambahkan efek animasi yang lebih banyak pada perangkat lunak ini sehingga tampilannya lebih menarik dan mudah dipahami.

3. Penambahan video dari seorang narator yang menjelaskan mengenai seluk-beluk dari setiap topik.

4. Penyusunan bahan yang diajarkan dalam bentuk yang lebih sistematik sehingga mempermudah user dalam melihat isinya. 


\section{DAFTAR PUSTAKA}

David Halliday, Robert Resnick, Jearl Walker, 2013, Fundamentals of Physics, John Wiley \& Sons, Inc.

Hutahaean, Harvei Desmond, 2012, Penerapan Computer Assisted Instruction Dalam Pembelajaran Pemahaman AlgoritmaCaesar Cipher, Jurnal Pelita Informatika ISSN 2301-9425-01,Volume 1 No. 1 Hal. 11, STMIK Budi Darma, Medan

Jogiyanto, 2009, Sistem Teknologi Informasi: Konsep Dasar, Teknologi, Aplikasi, Penerbit Andi, Yogyakarta

Jusuf, Heni, 2009, Perancangan Aplikasi Sistem Ajar Tematik Berbasis Multimedia, Jurnal Artifical ISSN 1978-9491, Volume 3 No. 1 Hal. 60, Universitas Nasional, Jakarta

Kanginan, M., 2005,Sains Fisika SMP Untuk Kelas VII Jilid 1A, Penerbit Erlangga, Jakarta

Mustikasari, Ardiani, 2008, Mengenal Media Pembelajaran, diakses dari http://eduarticles.com/mengenal-media-pembelajaran/, tanggal akses 28 Agustus 2011.

Madcoms, 2008, Microsoft Visual Basic 6.0 untuk Pemula, Penerbit Andi, Yogyakarta

Sutabri, Tata, 2012, Konsep Sistem Informasi,Penerbit Andi, Yogyakarta

Taylor, Charles, 2005, Science Encylopedia, King Fisher, London. 